\title{
Ocular findings and vision status of learners with oculocutaneous albinism
}

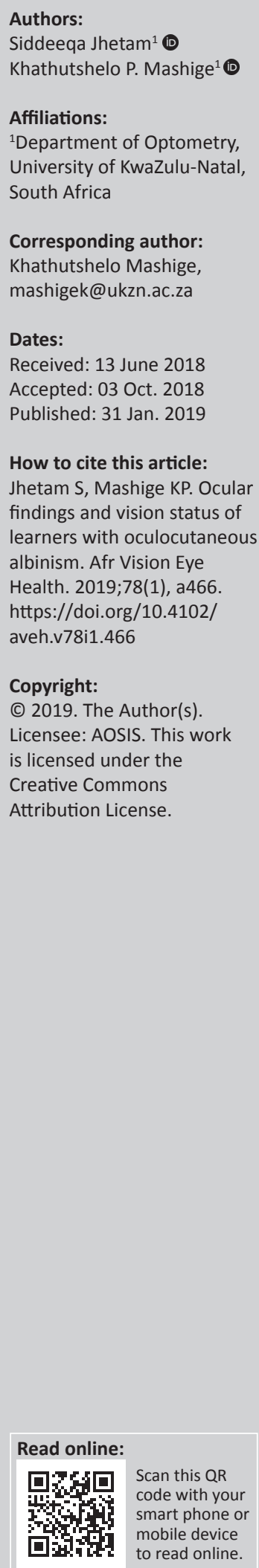

Background: Oculocutaneous albinism results in defects of the visual pathway and ocular structures.

Aim: To determine the ocular findings and vision status of learners with oculocutaneous albinism (OCA) as well as to establish the level of visual acuity, contrast sensitivity and reading rate improvements following optical correction.

Setting: Three special education schools in KwaZulu-Natal, South Africa.

Methods: A total of 81 learners with OCA participated in this study. Testing procedures included logMAR distance and near visual acuity (VA) measurements, cover tests, retinoscopy (dry), subjective refraction, tangent screen, ophthalmoscopy, contrast sensitivity and reading rate determination.

Results: The majority of participants (96.3\%) had wheat straw coloured hair and $95.1 \%$ had grey irides. All the learners presented with iris-transillumination and an absent foveal reflex and all but one exhibited nystagmus. Esophoria and esotropia represented $72.8 \%$ of binocular vision anomalies. Myopic astigmatism was noted in $41.4 \%$ of the learners while with the rule astigmatism was predominant (64\%). Following optical correction, VA significantly improved from a range of 0.50 to $1.40 \log \mathrm{MAR}$ to a range of 0.5 to $1.06 \log \mathrm{MAR}$ for distance $(p<0.05)$ and from a range of 0.40 to $1.30 \log \mathrm{MAR}$ to a range of 0.30 to $1.08 \log \mathrm{MAR})$ for near $(p<0.05)$. In addition, contrast sensitivity improved from a range of 0.48 to $1.92 \log C S$ to a range of 0.88 to $1.92 \log C S(p<0.05)$. However, the reading rate did not show any significant improvement following optical correction $(p>0.05)$.

Conclusion: Learners with OCA exhibited various ocular and vision defects which impair visual functions. Their VA and contrast sensitivity could be significantly improved with optical correction; however, their reading rate was not improved.

\section{Introduction}

Albinism is an autosomal recessive disorder that results from a reduction of pigmentation in the structures of the skin and eyes. ${ }^{1}$ There are two main types of albinism: oculocutaneous and ocular. Oculocutaneous albinism (OCA) affects the optical system, skin and hair, ${ }^{2}$ while ocular albinism $(\mathrm{OA})$ is characterised by a reduction of pigments in the eye and usually does not affect the colour of the skin and hair. Oculocutaneous albinism comprises four subtypes: OCA1, OCA2, OCA3 and OCA4, with each subtype presenting with a characteristic phenotype and visual acuity (VA). ${ }^{3}$

The classification of albinism is related to the affected genes, the most commonly affected ones being the tyrosinase gene on chromosome 11q14-21, which results in OCA1, and the $P$ gene on chromosome 15q11.2, which results in OCA2. Ocular albinism occurs because of mutations on chromosome Xp.22.3, which is X-linked (affecting men only), whereas OCA1 and OCA2 affect both men and women. ${ }^{4}$ The prevalence of OCA in Southern Africa has been reported to range between $0.02 \%$ and $0.1 \%$, with a male to female ratio ranging from 0.8 to $1.4: 1.5,6,7,8,9,10,11$ Several eye and vision problems including ocular hypopigmentation, reduced VA, nystagmus, strabismus and photophobia are associated with albinism. ${ }^{12}$

Refractive error changes have also been reported to be prevalent in albinism. ${ }^{13,14,15}$ For example, Keef $^{13}$ found a high prevalence (82\%) of hyperopic astigmatism in 28 children living with albinism, while Sacharowitz ${ }^{14}$ reported a prevalence of $52.5 \%$ myopic astigmatism in 40 subjects with OCA who presented to a low vision clinic in South Africa. Wolf et al ${ }^{15}$ reported a prevalence of $84 \%$ astigmatic ametropia among 38 children with albinism. Other important visual functions which affect many learners with OCA include contrast sensitivity and reading rate. Contrast is 
the difference in brightness between a target and its background and provides information relating to real-world environments. ${ }^{16}$ Reading rate refers to the number of correct words read per minute and is calculated as the total number of words read minus the number the reader added and/or omitted divided by $60 \mathrm{s.}{ }^{17}$ There is a paucity of literature investigating these important visual functions and the level of improvement that could be achieved following optical correction in persons with OCA.

The purpose of this study was to determine the ocular findings and vision status of learners with OCA as well as to establish the level of VA, contrast sensitivity and reading rate improvements following optical correction. The results of this study will assist eye care practitioners to make appropriate management options for learners with OCA early in their schooling careers. This is important as early interventions in this group can enhance their learning and educational abilities.

\section{Methods}

This was an observational study design involving convenience sampling conducted at three special education schools that catered to the needs of learners with visual impairments and those with multiple disabilities in the KwaZulu-Natal province of South Africa, located along the east coast of South Africa. The schools were Open Air, Ethembeni and Arthur Blaxall schools. At the time of this study, there were approximately 100 learners with OCA in the three schools who met the age requirements of the study. Eighty-one learners between the ages of 8 and 21 years agreed to participate in the study, giving a response rate of $81 \%$.

The presence of strabismus and heterophoria was investigated using the cover test, both at distance $(4 \mathrm{~m})$ and at near $(40 \mathrm{~cm})$, with and without optical correction. The unilateral cover test was used to determine the presence of a strabismus, while the alternating cover test was used to detect a heterophoria. If a heterophoria was observed, the condition was further investigated using a red Maddox rod and a penlight, with the rod being placed in front of the learner's right eye. A red lens and penlight were used to ascertain if suppression was present.

Distance and near visual acuities with and without optical correction were measured using a logMAR chart. Subjective spectacle correction was determined after objective refraction. Monocular and binocular visual acuities were measured. The test distance, the logMAR line VA and equivalent Snellen or Metre VA were then recorded and appropriate logMAR VA conversions were applied where necessary. Visual acuity with optical correction was further classified according to the World Health Organization classification of visual impairment. ${ }^{18}$ Contrast sensitivity was classified in accordance with the guidelines of the test utilised, the Mars Letter Contrast Sensitivity Test. A paediatric rate of reading chart $^{17}$ was utilised to determine the reading rate before and after optical correction. The number of words read and the number of words the learner added and/or omitted were recorded on the test record sheet. Using these values, the reading rate was calculated using the formula provided by the chart developers:

$$
\text { Reading rate }=\frac{\text { number of words read }- \text { errors }}{60 \text { seconds }}
$$

Data were analysed using the Statistical Package for Social Sciences (SPSS) version 24, with the distribution of data being tested for normality with the Kolmogorov-Smirnov test. The results of the Kolmogorov-Smirnov test indicated that all the data were normally distributed $(p>0.05)$. Pre- and postoptical intervention data for VA, contrast sensitivity and reading rate were analysed using the paired $t$-test, and a probability value of $<0.05$ was considered statistically significant.

\section{Ethical considerations}

Ethical approval to conduct the study was obtained from the University of KwaZulu-Natal's Biomedical Research and Ethics Committee (ethical clearance number: BFC054/14) and permission was granted by the respective schools as well as other relevant bodies. The study adhered to the tenets of the Declaration of Helsinki and written informed assents and consents were obtained from all the learners and/or parents / guardians.

\section{Results}

A total of 81 learners, consisting of 48 (59.3\%) female and 33 (40.7\%) male learners, from Arthur Blaxall, Open Air and Ethembeni schools participated in this study. The number of learners from Arthur Blaxall, Open Air and Ethembeni schools was $40(49.4 \%), 25(30.9 \%)$ and $16(19.8 \%)$, respectively. The age of the participants ranged from 8 to 21 years (mean $=13.7$ \pm 3.42 years). All the learners reported reduced vision at both distances (distance and near) and all but one reported sensitivity to light. Seventy-eight (96.3\%) learners had wheat straw coloured hair, two $(2.5 \%)$ had brown hair and one $(1.2 \%)$ had white hair. Seventy-seven (95.1\%) learners had grey irides and four $(4.9 \%)$ had brown irides. All the learners presented with typical characteristic features of OCA including iris trans-illumination and the absence of a foveal reflex.

Eighty (98.8\%) learners presented with horizontal pendular constant conjugate nystagmus and one (1.2\%) did not have nystagmus. The characteristics of the nystagmus were grossly observed by the researcher and that varied when learners fixated at near and distant targets. Many learners (81.5\%) showed no change in amplitude but an increase in speed at near points compared to distant points. The contrary was true for $4.9 \%$ of the learners in whom the speed increased at distance compared to near points of fixation. There was no difference in the amplitude and speed of nystagmus for near and distance points in $4.9 \%$ of the learners. The amplitude of nystagmus increased at near; however, speed remained constant in $1.2 \%$ of the learners. There was no noticeable nystagmus in $1.2 \%$ of learners. 
Ocular motilities (saccades and pursuits), visual field testing using the Amsler grid and tangent screen, yielded inconclusive results because of the presence of nystagmus in all but one participant.

Esophoria was prevalent in a significant proportion of learners $(32.1 \%)$, followed by alternating esotropia (22.2\%). The results of ocular alignment tests (cover and Maddox rod tests), with optical compensation, were the same as those without optical correction. Figure 1 shows the numbers and percentages of the different types of binocular vision conditions in the study sample.

Forty-nine (60.5\%) learners were suppressing one eye and 32 $(39.5 \%)$ learners were not. Astigmatism was the most frequent refractive error type observed in both the right eye (RE) and left eye (LE). Myopic astigmatism was present in $41.4 \%$ of learners, followed by hyperopic astigmatism (38.9\%). The most common type of astigmatism was with the rule (64\%) (Table 1).

The minimum, maximum and mean unaided and optically corrected $\log$ MAR distance VA values of the learners are shown in Table 2. The mean binocular unaided distance VA $(0.80 \pm 0.15 \log \mathrm{MAR})$ was better than the mean monocular acuities (RE: $0.93 \log M A R \pm 0.18, \mathrm{LE}: 0.89 \log \mathrm{MAR} \pm 0.18$ ). The mean VA with optical correction achieved with both eyes (0.69 $\log$ MAR \pm 0.14$)$ was better than mean monocular acuities (RE: $0.78 \log$ MAR \pm 0.13, LE: $0.74 \log$ MAR \pm 0.13 ). The distance VA obtained with optical correction was statistically significantly better than VA values achieved

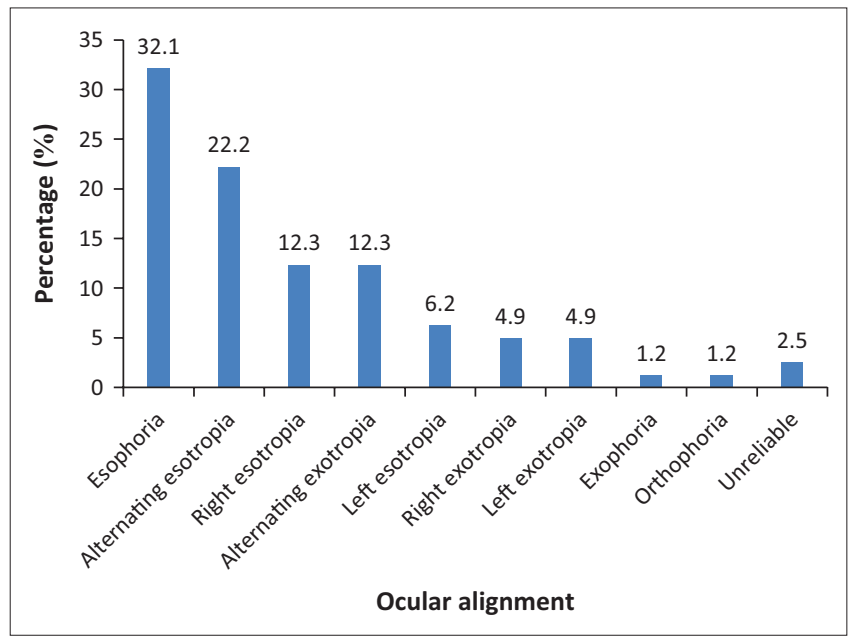

FIGURE 1: The percentages of ocular alignment conditions detected using the cover and Maddox rod tests.

TABLE 1: Refractive error findings.

\begin{tabular}{lcc}
\hline Refractive error & Number $(\boldsymbol{N})$ & Percentage \\
\hline Myopic astigmatism & 67 & 41.4 \\
Hyperopic astigmatism & 63 & 38.9 \\
Hyperopia & 15 & 9.3 \\
Myopia & 8 & 4.9 \\
Simple astigmatism & 6 & 3.7 \\
Emmetropia & 3 & 1.9 \\
\hline Total & $\mathbf{1 6 2}$ & $\mathbf{1 0 0}$ \\
\hline
\end{tabular}

without optical correction $(p=0.000$ ) (Table 2). Optical correction improved the distance vision of 145 eyes (89.5\%), while the distance vision of 14 eyes $(8.6 \%)$ remained the same with and without correction; however, three eyes $(1.9 \%)$ did not require optical correction.

Eight eyes $(4.9 \%)$ were classified as having severe visual impairment, and all other eyes (95.1\%) had moderate visual impairment according to the World Health Organization classification of visual impairment. The minimum, maximum and mean unaided and optical corrected logMAR near VA values at $40 \mathrm{~cm}$ for the RE, LE and both eyes (BE) of the learners are shown in Table 3 . Unaided VA at $40 \mathrm{~cm}$ ranged from $0.30 \log \mathrm{MAR}$ to $1.30 \log \mathrm{MAR}$. The unaided VA range obtained binocularly ( $0.30 \log$ MAR-1.02 logMAR) was better than that of the monocular VA (RE: $0.50 \operatorname{logMAR}-1.30$ logMAR; LE: $0.4 \log$ MAR - $1.30 \log$ MAR). Visual acuity measured for near $(40 \mathrm{~cm})$ with optical correction ranged between $0.30 \log$ MAR and $1.10 \log$ MAR. Mean binocular VA $(0.65 \log$ MAR \pm 0.16$)$ was better than the mean monocular VA (RE: $0.76 \log M A R \pm 0.15 ; \mathrm{LE}: 0.74 \log M A R \pm 0.15)$. The difference between the mean near $\log M A R$ visual acuities measured with and without optical correction ranged from $0.06 \log$ MAR to $0.11 \log$ MAR, with optical corrected acuity being statistically significantly better $(p<0.00)$ (Table 3 ). Optical correction improved the near vision of 127 eyes $(78.4 \%)$, while the near vision of 30 eyes $(18.5 \%)$ remained the same with and without correction; three eyes (1.9\%) did not require optical correction and the near vision of one eye $(0.6 \%)$ decreased.

Uncorrected logMAR VA determined at $25 \mathrm{~cm}$ was compared to values at $40 \mathrm{~cm}$. Sixty-one eyes $(37.7 \%)$ showed better vision at $25 \mathrm{~cm}, 60$ eyes (37\%) had worse vision at $25 \mathrm{~cm}$ and there was no difference found in 33 eyes (20.4\%). Similarly, $\log$ MAR VA with optical correction at $25 \mathrm{~cm}$ and $40 \mathrm{~cm}$ was compared. Ninety eyes (55.6\%) exhibited worse vision at $25 \mathrm{~cm}, 37(22.8 \%)$ had better vision at $25 \mathrm{~cm}$ while only $24(14.8 \%)$ showed no difference in VA.

TABLE 2: LogMAR distance visual acuity without and with optical correction.

\begin{tabular}{llcccc}
\hline Eye & Status & $\begin{array}{c}\text { Minimum } \\
\text { (logMAR) }\end{array}$ & $\begin{array}{c}\text { Maximum } \\
\text { (logMAR) }\end{array}$ & $\begin{array}{c}\text { Mean } \\
\text { (logMAR) }\end{array}$ & $p$ \\
\hline RE & Unaided & 0.52 & 1.40 & $0.93 \pm 0.18$ & 0.000 \\
& Optical correction & 0.50 & 1.06 & $0.78 \pm 0.13$ & \\
LE & Unaided & 0.50 & 1.32 & $0.89 \pm 0.18$ & 0.000 \\
& Optical correction & 0.50 & 1.10 & $0.74 \pm 0.13$ & \\
BE & Unaided & 0.44 & 1.12 & $0.80 \pm 0.15$ & 0.000 \\
& Optical correction & 0.40 & 1.00 & $0.69 \pm 0.14$ & \\
\hline
\end{tabular}

$R E$, right eye; $L E$, left eye; $B E$, both eyes.

TABLE 3: LogMAR near $(40 \mathrm{~cm})$ without and with optical correction.

\begin{tabular}{llcccc}
\hline Eye & Status & $\begin{array}{c}\text { Minimum } \\
\text { (logMAR) }\end{array}$ & $\begin{array}{c}\text { Maximum } \\
\text { (logMAR) }\end{array}$ & $\begin{array}{c}\text { Mean } \\
\text { (logMAR) }\end{array}$ & $p$ \\
\hline RE & Unaided & 0.50 & 1.30 & $0.87 \pm 0.17$ & 0.000 \\
& Optical correction & 0.40 & 1.08 & $0.76 \pm 0.15$ & \\
\multirow{2}{*}{ LE } & Unaided & 0.40 & 1.30 & $0.84 \pm 0.17$ & 0.000 \\
& Optical correction & 0.50 & 1.10 & $0.74 \pm 0.13$ & \\
$\mathrm{BE} \quad$ & Unaided & 0.30 & 1.02 & $0.71 \pm 0.18$ & 0.001 \\
& Optical correction & 0.30 & 0.92 & $0.65 \pm 0.16$ & \\
\hline
\end{tabular}

$\mathrm{RE}$, right eye; $\mathrm{LE}$, left eye; $B E$, both eyes. 
TABLE 4: Contrast sensitivity $(\log C S)$ without and with optical correction.

\begin{tabular}{llccccc}
\hline Eye & \multicolumn{1}{c}{ Status } & $\begin{array}{c}\text { Number } \\
(\boldsymbol{N})\end{array}$ & $\begin{array}{c}\text { Minimum } \\
(\log C S)\end{array}$ & $\begin{array}{c}\text { Maximum } \\
(\log C S)\end{array}$ & $\begin{array}{c}\text { Mean } \\
(\log C S)\end{array}$ & $p$ \\
\hline $\mathrm{RE}$ & Unaided & 80 & 0.56 & 1.88 & $1.43 \pm 0.26$ & 0.000 \\
& Optical correction & 79 & 0.88 & 1.88 & $1.52 \pm 0.24$ & \\
LE & Unaided & 80 & 0.48 & 1.92 & $1.42 \pm 0.33$ & 0.000 \\
& Optical correction & 78 & 0.92 & 1.92 & $1.53 \pm 0.25$ & \\
BE & Unaided & 27 & 0.76 & 1.92 & $1.57 \pm 0.27$ & 0.004 \\
& Optical correction & 27 & 1.32 & 1.92 & $1.68 \pm 0.18$ & \\
\hline
\end{tabular}

$R E$, right eye; $L E$, left eye; $B E$, both eyes.

TABLE 5: Minimum, maximum and mean reading rate values obtained without and with optical correction.

\begin{tabular}{lccccc}
\hline Status & $\begin{array}{c}\text { Number } \\
(N)\end{array}$ & $\begin{array}{c}\text { Minimum } \\
\text { (words per } \\
\text { minute) }\end{array}$ & $\begin{array}{c}\text { Maximum } \\
\text { (words per } \\
\text { minute) }\end{array}$ & $\begin{array}{c}\text { Mean (words } \\
\text { per minute) }\end{array}$ & $p$ \\
\hline Unaided & 65 & 21 & 140 & $64.6 \pm 26.61$ & 0.448 \\
Optical correction & 61 & 7 & 119 & $62.2 \pm 25.66$ & \\
\hline
\end{tabular}

Uncorrected $\log$ contrast sensitivity $(\log C S)$ values ranged between $0.48 \log C S$ and $1.92 \log C S$ (Table 4 ). The mean values for the RE, LE and BE were $1.43 \pm 0.26 \log C S, 1.42 \pm$ $0.33 \log C S$ and $1.57 \pm 0.27 \log C S$, respectively. Contrast sensitivity values without optical correction showed that moderate loss of contrast sensitivity occurred mostly monocularly (RE: 51.9\%, LE: 46.9\%), while those for binocular measurements were mostly normal (14.8\%). There was equally statistically significant difference between $\log C S$ values determined without and with optical correction $(p<$ 0.05) (Table 4). Log contrast sensitivity ( $\log C S)$ measured with optical correction was greatest binocularly (mean $=1.68$ $\pm 0.18 \log$ CS). The range of optically corrected contrast sensitivity was $0.88 \log C S-1.92 \log C S$ (Table 4). Despite optical correction, moderate loss of contrast sensitivity (CS) was still the predominant classification for monocular contrast sensitivity values. However, the number of normal CS values increased from 11, 18 and 12 without optical correction to 18,25 and 14 with spectacle correction for the $\mathrm{RE}, \mathrm{LE}$ and BE, respectively.

Reading rates of the better-seeing eye obtained before and after optical correction are presented in Table 5.

\section{Discussion}

Albinism is a genetically inherited disorder that affects learners and their families medically, socially and psychologically. $3,4,5$ Apart from the visual impairment, their distinctive phenotype of pale, chalky, de-pigmented skin, sandy coloured hair and blue to hazel eyes leads to social discrimination and stigmatisation..$^{3,45}$ In the current study, there were more female than male learners with OCA; this gender distribution is similar to other reports by Lund and Gaigher ${ }^{9}$ and Lund et al. ${ }^{10}$ in the Limpopo province of South Africa. The typical phenotypic characteristics of wheat straw coloured hair, brown or white hair seen in this group are because of reduced melanin pigment biosynthesis. ${ }^{3}$ Raliavhegwa ${ }^{8}$ reported similar results among 153 black South African learners aged between 7 and 17 years with OCA from the Limpopo province, suggesting that this is the normal hair distribution in persons with OCA.
The photophobia reported by the learners is a result of significant light scattering within the eye because of a decrease in light filtering by the pigment of the eye, leading to reduced image contrast. ${ }^{19}$ In addition, the high levels of retinal irradiance occur because of the lack of pigments in the uvea and retina of learners with OCA. Abadi and Pascal ${ }^{20}$ further suggested that discomfort and disability glare that is usually experienced by persons with OCA is a result of light scattered by the iris causing multiple internal reflections.

All the learners had iris trans-illumination and an absent foveal reflex; these are because of the reduction of melanin in the iris, resulting in a decrease in light filtering from the retina and a subsequent increase in reflected light back to the iris. ${ }^{19}$ Pigment changes affect ocular structures such as the iris, fundus and macula; as a result, light reflected from the retina is not filtered by the iris as it has reduced pigments, with the iris appearing pink in areas deficient in pigments because of the reflection of the retina. This condition is called iris trans-illumination ${ }^{19}$ and has been used as an index to indicate the light scattering effect of the iris. ${ }^{20}$ The majority of the learners presented with nystagmus because of foveal hypoplasia and misrouting of visual projection fibres. ${ }^{15}$ The absence of nystagmus found in one learner is though rare, also been reported by Levin and Stroh. ${ }^{1}$ Horizontal pendular constant conjugate nystagmus was observed in the majority of the learners. Horizontal nystagmus has been reported to be the predominant nystagmus in persons with OCA. ${ }^{21}$ In addition, Levin and Stroh $^{1}$ reported that the characteristics of nystagmus in persons with albinism are such that in the early stages it has a large amplitude and low frequency; however, with time, pendular nystagmus develops and subsequently becomes jerky.

The features of nystagmus were different at distance and near viewing as the majority of learners had increased velocity of nystagmus at near positions compared to distance. However, in a few learners, there was no difference in amplitude and velocity at both fixating positions. In some cases, only the amplitude increased while the velocity remained the same. This finding could possibly be related to vision reduction at near and accommodation status of the learners. However, further investigations are required to confirm this. The increase in velocity of nystagmus at near positions is in contradiction to findings by Biswas and Lloyd, ${ }^{21}$ who reported a dampening of nystagmus during convergence.

Perez-Carpinell et al. ${ }^{12}$ and Summers ${ }^{19}$ concluded that there was a high prevalence of strabismus in persons with albinism. This is supported by the findings of this study as the majority of learners presented with heterotropia (62.8\%). Raliavhegwa ${ }^{8}$ also reported a $34.6 \%$ prevalence of heterophoria in children with albinism in the Northern Province (now Limpopo) of South Africa. The presence of strabismus has been associated with abnormal visual cortex development. ${ }^{22}$ Many ocular abnormalities develop because of the lack of melanin; thus, 
ocular structures do not develop normally. Cells in the primary visual cortex, which are 'binocularly driven', are also affected during development and may lead to the occurrence of strabismus..22 Misrouting of optic fibres has also been associated with the development of strabismus. ${ }^{3}$ The high prevalence of tropic conditions may have also attributed to $60.5 \%$ of the learners experiencing suppression in one eye.

Many learners had astigmatism in both the RE and LE, suggesting that astigmatism is the most frequent refractive error type observed in this group. The high prevalence of astigmatism in persons with albinism has also been reported in other studies. ${ }^{8,13,14,15,23,24}$ Reduced vision may result from refractive error, misalignment of the eyes, reduced pigments in the macula, misrouting of optic nerve fibres, amblyopia and nystagmus, ${ }^{15}$ as well as foveal hypoplasia. ${ }^{3}$ Uncorrected $\log$ MAR distance VA in the RE, LE and BE was within the suggested range for persons with OCA type 2.,25 GrØnskov et al. ${ }^{3}$ suggested the range of uncorrected VA in persons with albinism to be $20 / 400(6 / 120,1.30 \log$ MAR) to $20 / 66$ (6/20, $0.50 \log$ MAR), while Loshin and Browning ${ }^{25}$ reported a range of 20/400 (6/120, $1.3 \log$ MAR) to 20/30 (6/9, $0.2 \log$ MAR). The results of uncorrected VA obtained in the current study also agree with findings reported in other studies. ${ }^{11,26,27}$

Optical correction improved distance logMAR VA up to a range of $0.40 \log$ MAR - $1.10 \log$ MAR. Raliavhegwa ${ }^{8}$ also reported an improvement in distance logMAR VA following optical correction in a study conducted in the Limpopo province of South Africa among children with OCA. In addition, Sacharowitz ${ }^{14}$ reported significant improvements with optical correction in distance vision of $60 \%(n=40)$ of patients with albinism presenting at a low vision clinic at the university. Other studies ${ }^{11,27}$ reported similar improvements in the mean logMAR distance VA following optical correction. Clinically, the improvement of distance vision ranged from 4 letters $(0.08 \log$ MAR) to 9 letters $(0.18 \log$ MAR). Despite this significant improvement $(p=0.000)$, the mean logMAR distance acuity with optical correction was worse than 0.3 $\log$ MAR $(6 / 12,20 / 40)$, showing that optical correction alone did not improve distance vision to an 'acceptable functional

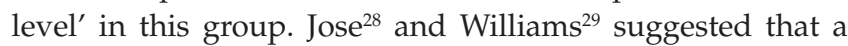
minimum VA of $20 / 40(6 / 12)(0.3 \log$ MAR) is required to perform most tasks at distance.

Uncorrected near $(40 \mathrm{~cm}) \log$ MAR VA for the RE, LE and BE ranged between $0.30 \log$ MAR and $1.30 \log$ MAR $(0.8 \mathrm{M}$ and $8 \mathrm{M})$. However, the near VA at $40 \mathrm{~cm}$ with optical correction was significantly better (0.30 logMAR-1.10 logMAR [0.8M $5 \mathrm{M}]$ ) than acuities obtained without optical correction (all $p$-values $<0.00)$. This improvement equated to a minimum gain of 1.5-6.5 letters. This suggests that just like distance VA, optical correction significantly improved near VA. According to Lovie-Kitchin and Whittaker, ${ }^{30}$ a VA range of $0.8 \mathrm{M}-5 \mathrm{M}$ (at $40 \mathrm{~cm}$ ) might provide sufficient acuity to read medicine labels, newspaper, magazines, books and large print books. It is therefore recommended that learners with OCA should be given a comprehensive eye examination routinely including measurement and correction of near vision. Pereira et al. ${ }^{31}$ also found a range of $0.10 \log$ MAR - $0.70 \log$ MAR $(0.5 \mathrm{M}-$ 2.0M) VA improvement following optical correction, further supporting the importance of near vision correction in persons with OCA. Here too, the least improvement with optical correction did not achieve a functional reading VA level of $1 \mathrm{M}$ (0.40 logMAR). The functional level would allow a person to read a newspaper print at $40 \mathrm{~cm}$; thus, even with optical correction the learners would not achieve this task.

When uncorrected and corrected $\log$ MAR VA obtained at $25 \mathrm{~cm}$ and $40 \mathrm{~cm}$ was compared, it remained the same in $33(20.4 \%)$ and 24 (14.8\%) eyes, respectively. Despite optical correction significantly improving vision, the VA at $25 \mathrm{~cm}$ was worse in $55.7 \%$ of the eyes tested. This observation requires further investigations including nystagmus and accommodative status testing.

Contrast sensitivity before optical correction ranged from $0.48 \log C S-1.92 \log C S$ and it improved following optical correction. The Mars Letter Contrast Sensitivity Test at $50 \mathrm{~cm}$ allows for a maximum of $1.92 \log C S$ to be perceived; therefore, the maximum $\log C S$ value for some learners might be greater than $1.92 \log C S$. Several contrast sensitivity studies $^{8,11,25}$ have been conducted using various stimuli. These studies represented contrast sensitivity levels using spatial frequencies ${ }^{8}$ and percentages. ${ }^{11}$ The current study utilised $\log C S$ values; therefore, it is difficult to make comparisons of the contrast sensitivity levels of this study with that of other studies. However, all the studies reported that albinism is associated with reduced contrast sensitivity.

In this study, there was no statistically significant difference in the reading rate determined before and after optical correction. This finding may have been influenced by the method used to determine the reading rate. For instance, the logMAR VA for the reading rate was chosen as one line above the VA achieved for both pre- and post-optical corrections. Considering the method used to obtain the VA, a significant acuity reserve was not considered. Acuity reserve is important to allow for fluent reading speed and, therefore, not accounting for sufficient acuity reserve might have impacted the reading rate achieved in this study.

Limitations of this study include the omission of amplitude of accommodation, colour vision and stereopsis assessments. Cycloplegia could not be applied as the study also investigated near VA and cycloplegia affects near vision functions.

\section{Conclusion}

Learners with OCA from the three schools presented with varying types of visual defects. Optical correction significantly improved VA and contrast sensitivity in learners with OCA; however, reading rate did not improve. Early visual examination and the provision of appropriate correction to this group are required to improve the visual function. 


\section{Acknowledgements}

The authors thank all the learners from the three schools who participated in this study. They also thank Ms Carrin Martin for reviewing this article and giving valuable comments.

\section{Competing interests}

The authors declare that they have no financial or personal relationships that may have inappropriately influenced them in writing this article.

\section{Authors' contributions}

S.J. conducted the research for a Master's degree in Optometry, under the supervision of K.P.M. Both authors contributed and finalised the article.

\section{References}

1. Levin AV, Stroh E. Albinism for the busy clinician. JAAPOS. 2011;15(1):59-66. https://doi.org/10.1016/j.jaapos.2010.10.012

2. Oetting WS, Brilliant $M H$, King RA. The clinical spectrum of albinism in humans. Mol Med Today. 1996;2(8):330-335. https://doi.org/10.1016/1357-4310(96) 81798-9

3. GrØnskov K, Ek J, Brondum-Nielsen K. Oculocutaneous albinism. Orph J Rare Dis [serial online]. 2007 [cited 2013 Oct 31]. Available from: http://www.OJRD.com/ content/2/1/43

4. Summers CG. Albinism: Classification, clinical characteristics, and recent findings. Optom Vis Sci. 2009;86(6):659-662. https://doi.org/10.1097/OPX.0b013e31 81a5254c

5. Lund PM, Puri N, Durham-Pierre D, King RA, Brilliant MH. Oculocutaneous albinism in an isolated Tonga community in Zimbabwe. J Med Genet. 1997;34:733735. https://doi.org/10.1136/jmg.34.9.733

6. Kromberg JGR, Jenkins T. Prevalence of albinism in the South African Negro. S Afr Med J. 1982;61:383-386.

7. Lund PM. Distribution of oculocutaneous albinism in Zimbabwe. J Med Genet 1996;33:641-644. https://doi.org/10.1136/jmg.33.8.641

8. Raliavhegwa M. Vision problems among children with oculocutaneous albinism attending special education schools in the Northern Province of South Africa [unpublished dissertation]. Polokwane, South Africa: University of the North 2001.

9. Lund PM, Gaigher R. A health intervention programme for children with albinism at a special school in South Africa. Health Educ Res. 2002;17(3):365-372. https:// doi.org/10.1093/her/17.3.365

10. Lund PM, Maluleke TG, Gaigher I, Gaigher MJ. Oculocutaneous albinism in a rura community of South Africa: A population genetic study. Annals Hum Biol. 2007;34(4):493-497. https://doi.org/10.1080/03014460701401261

11. Schwering MS, Kumar N, Bohrmann D, et al. Refractive errors, visual impairment, and the use of low-vision devices in albinism in Malawi. Graef Arch Clin Exp Ophthalmol. 2015;253:655-661. https://doi.org/10.1007/s00417-015-2943-0
12. Perez-Carpinell J, Capilla P, Illueca C, Morales J. Vision defects in Albinism. Optom Vis Sci. 1992;69(8):623-628. https://doi.org/10.1097/00006324-19920800000005

13. Keefe JE. Albinism: Assessment and educational implications. Paper presented at: The International Conference on Low Vision 1990. Proceedings of Low Vision Ahead II: The International Conference on Low Vision; 1990 Mar 13-16. Melbourne, Australia: Association for the Blind; 1990. p. 127-131.

14. Sacharowitz HS. An overview of oculocutaneous albinism in South Africa. Paper presented at: The International Conference on Low Vision 1999. Proceedings of the Low Vision Rehabilitation: Assessment, Intervention and Outcomes, International Conference on Low Vision; Swets \& Zeitlinger, New York; 1999. p. 41-46.

15. Wolf $A B$, Rubin SE, Kodsi SR. Comparison of clinical findings in pediatric patients with albinism and different amplitudes of nystagmus. JAAPOS. 2005:9:363-368. https://doi.org/10.1016/j.jaapos.2005.03.003

16. Pelli DG, Bex P. Measuring contrast sensitivity. Vis Res. 2013;90:10-14. https:// doi.org/10.1016/j.visres.2013.04.015

17. Nirghin U. Design, reliability and validity of a paediatric rate of reading chart [unpublished dissertation]. South Africa: University of KwaZulu-Natal; 2012.

18. World Health Organization (WHO). Visual impairment and blindness [homepage on the Internet]. Fact Sheet No. 282, c2014 [updated Aug 2014; cited 2014 Aug 18]. Available from http://www.who.int/mediacentre/factsheets/fs282/en/

19. Summers CG. Vision in albinism. Trans Am Ophthalmol Soc. 1996;94:1095-1155.

20. Abadi R, Pascal E. The recognition and management of albinism. Ophthal Physiol Opt. 1989;9:3-15. https://doi.org/10.1111/j.1475-1313.1989.tb00797.x

21. Biswas S, Lloyd IC. Oculocutaneous albinism. Arch Dis Child. 1999;80:565-569. https://doi.org/10.1136/adc.80.6.565

22. Lee KA, King RA, Summers CG. Stereopsis in patients with albinism: Clinical correlates. JAAPOS. 2001;5(2):98-104. https://doi.org/10.1067/mpa.2001. 112441

23. Wildsoet CF, Oswald PJ, Clark S. Albinism: Its implications for refractive development. Invest Ophthalmol Vis Sci. 2000;41(1):1-7.

24. Khanal S, Pokharel A, Kandel H. Visual deficits in Nepalese patients with oculocutaneous albinism. J Optom. 2016;9:102-109. https://doi.org/10.1016/j. optom.2015.01.002

25. Loshin DS, Browning RA. Contrast sensitivity in albinotic patients. Am J Optom Physiol Opt. 1983;6(3):158-166. https://doi.org/10.1097/00006324-19830300000003

26. Anderson J, Lavoie J, Merrill K, King RA, Summers CG. Efficacy of spectacles in persons with albinism. JAAPOS. 2004;8(6):515-520. https://doi.org/10.1016/j. jaapos.2004.08.008

27. Udeh NN, Eze BI, Onwubiko SN, Arinze OC, Onwasigwe EN, Umeh RE. Oculocutaneous albinism: Identifying and overcoming barriers to vision care in a Nigerian population. J Comm Health. 2013;39:508-513. https://doi.org/10.1007/ s10900-013-9787-5

28. Jose RT. Treatment options. In: Jose RT, editor. Understanding low vision. New York: American Foundation for the Blind, 1983; p. 211-248.

29. Williams DR. Low vision distance systems II: Telescopes and telemicroscopes. In: Brilliant RL, editor. Essentials of low vision practice. Woburn: ButterworthHeinemann, 1999; p. 147-200.

30. Lovie-Kitchin JE, Whittaker SG. Prescribing near magnification for low vision patients. Clin Exp Optom. 1999;82(6):214-224. https://doi.org/10.1111/j.14440938.1999.tb06651.x

31. Pereira DFL, Araujo EL, Patuzzo FVD. Profile of albinism with low vision and improvement of visual acuity with the adaptation of optical and/or electronic resources. Rev Bras De Oftalmol. 2016;75(6):456-460. https://doi.org/10.5935/ 0034-7280.20160092 